\title{
SISTEM PEMANTAU KEKERUHAN AIR DAN PEMBERI MAKAN OTOMATIS PADA IKAN BERBASIS MIKROKONTROLER
}

\author{
Riskan Oktafiadi \\ Program Studi Teknik Elektro, Fakultas Teknologi Industri, Universitas Ahmad Dahlan \\ Kampus III UAD, Jl. Prof. Dr. Soepomo, Janturan, Yogyakarta 55161 \\ e-mail: riskanoktafiadi@yahoo.com
}

\begin{abstract}
Abtract
Industrial farming is usually do manually feeding or by using human power. Delaying in feeding when we go on traveling in a long time, causing the growth and durability of the fish will bereduced so that the production is not satisfacted and the harvest will be delayed. In other to delays in feeding, water turbidity also affects the level of production. Turbidity is an organic or inorganic ingredients contained in waters that affect the life processes of organisms that exist in these waters. Through this research has been developed a tool which is capable to do automatically feeding the fish in order to help the work of fish farmers. This tool was designed with acrylic as the main circumstance and ATmega8535 microcontroller circuit as a controller tool. In addition, this tool also uses RTC (Real Time Clock) and GE turbidity sensors that has fuction as storage time to feed fish and measure water turbidity levels in fish pond. Test of the tool has been done in several stages. The first stage is measuring the amount of feed that is shed by the tool in order to obtain the ideal weight for fish feed and the second stage is to take some of the water sample of fish pond, before the first sensor will be calibrated by dipping into the clear water in order to obtain the initial value of 0 , then the sensor will be tested on a sample of the fish pond water. This research has been successful, because the tool is able to work well to give fish feed automatically where the test within every 2 seconds on data which has been obtained by the research is linear. Beside, the turbidity sensor usage is able to measure water turbidity level from 4 fish pond with different turbidity levels in accordance with the pool water legible sample.
\end{abstract}

Keywords: a feeder automatically; RTC (Real Time Clock); microcontroller ATmega8535; sensor GE turbidity

\section{Abstrak}

Pada industri peternakan biasanya dilakukan pekerjaan pemberian makanan secara manual atau dengan menggunakan tenaga manusia. Keterlambatan pemberian pakan ikan apabila ditinggal berpergian petaninya dalam waktu yang lama, menyebabkan pertumbuhan dan daya tahan ikan berkurang sehingga hasil produksi tidak memuaskan serta panen menjadi terlambat. Selain keterlambatan pemberian pakan, kekeruhan (turbidity) air juga mempengaruhi tingkat produksi. Kekeruhan (turbidity) merupakan kandungan bahan organik maupun anorganik yang terdapat di perairan sehingga mempengaruhi proses kehidupan organisme yang ada di perairan tersebut. Melalui penelitian ini dikembangkan alat yang mampu memberi pakan ikan secara otomatis agar dapat membantu meringankan kerja para peternak ikan. Alat ini di desain dengan acrylic sebagai bahan utamanya dan rangkaian mikrokontroler ATmega8535 sebagai pengendali alat. Selain itu alat ini juga menggunakan RTC (Real Time Clock) dan sensor GE turbidity yang berfungsi sebagai penyimpan waktu untuk memberi pakan pada ikan dan mengukur tingkat kekeruhan pada air kolam ikan. Pengujian alat ini dilakukan dengan beberapa tahap. Tahap pertama menimbang banyaknya pakan yang ditumpahkan oleh alat agar didapat berat pakan yang ideal bagi ikan dan tahap kedua adalah dengan mengambil beberapa sempel air kolam ikan, dimana sebelum melakukan pengujian sensor terlebih dahulu dikalibrasi dengan mencelupkannya ke air jernih agar didapat nilai awal 0, setelah itu sensor diuji pada sempel air 
kolam ikan tersebut Penelitian ini telah berhasil, karena alat mampu bekerja dengan baik yaitu memberikan pakan ikan secara otomatis dimana pada pengujiannya dengan rentang waktu pemberian tiap 2 detik hasil data yang diperoleh adalah linear. Selain itu sensor turbidity yang digunakan mampu untuk mengukur tingkat kekeruhan air dari 4 kolam ikan dengan tingkat kekeruhan yang berbeda sesuai dengan sempel air kolam yang terbaca. .

Kata Kunci: pemberi pakan secara otomatis; RTC (Real Time Clock); mikrokontroler Atmega8535; sensor GE turbidity

\section{Pendahuluan}

Budidaya ikan air tawar merupakan salah satu mata pencarian masyarakat yang semakin hari bertambah peminatnya. Mayoritas masyarakat yang menjadi peternak ikan menggunakan cara tradisional dalam membudidayakannya. Cara yang digunakan peternak ikan hingga saat ini masih dinilai kurang efektif, sehingga hasil yang didapatkan tidak memuaskan.

Pemberian pakan tepat waktu dan parameter air merupakan aspek penting dalam budidaya ikan. Keterlambatan pemberian pakan ikan apabila ditinggal berpergian petaninya dalam waktu yang lama, menyebabkan pertumbuhan dan daya tahan ikan berkurang sehingga hasil produksi tidak memuaskan serta panen menjadi terlambat. Frekuensi pemberian pakan pada budidaya ikan adalah tiga kali sehari, yaitu pagi, sore, dan malam hari. Bobot pemberian pakan adalah 3 sampai dengan $5 \%$ dari berat total biomassa ikan.

Perancangan alat ini menggunakan sensor GE turbidity untuk mengukur tingkat kekeruhan air kolam ikan dan motor servo yang berfungsi membuka plat wadah pakan ikan sehingga pakan yang berada dalam wadah dapat ditumpahkan. Selanjutnya data dari sensor tersebut akan diolah oleh Mikrokontroler sebagai pengendali. Nantinya akan dihasilkan keluaran berupa tulisan warning pada LCD diikuti dengan nyala LED apabila nilai kekeruhan melewati batas ambang yang telah ditentukan..

\section{Metode Penelitian}

\subsection{Bahan Utama yang Digunakan}

Berikut fungsi dari masing-masing bahan penelitian dapat dilihat pada Tabel 1.

Tabel 1.Fungsi bahan penelitian

\begin{tabular}{ll}
\hline Nama Bahan & Fungsi \\
\hline Sensor GE Turbidity & Membaca tingkat kekeruhan air \\
\hline RTC sistem & Sebagai penyimpan tanggal, waktu sebagai input data \\
& waktu mikrokontroler \\
\hline Motor Servo & Sebagai pembuka dan penutup katup plat pakan ikan \\
\hline Minisistem mikrokontroler & Minisistem mikrokontroler merupakan modul kontrol \\
& yang digunakan untuk menyimpan dan mengeksekusi \\
& program. Mikrokontroler merupakan piranti utama \\
& pada sistem aplikasi ini. Keseluruhan sistem \\
& dikendalikan oleh mikrokontroler, mulai dari \\
& pembacaan sensor, dan menggerakkan motor servo \\
& plat pakan. \\
\hline Rangkaian Opamp & Sebagai penguat tegangan pada sensor agar lebih \\
& sensitive dalam pengukuran \\
\hline Kotak Acrylic & Tempat diletakkannya keseluruhan sistem dan sebagai \\
& wadah pakan ikan \\
\hline
\end{tabular}

\subsection{Perancangan Sistem}

Perancangan sistem dipresentasikan dalam bentuk blok diagram. Blok-blok diagram inilah yangakan membantu pembuatan perancangan alat pemantau kekeruhan air dan pakan ikan otomatis.Blok diagram rancangan dan sistem kerja alat tersebut dapat dilihat pada Gambar 1. 
Jurnal IImu Teknik Elektro Komputer dan Informatika (JITEKI)

Vol. 2, No. 1, Juni 2016

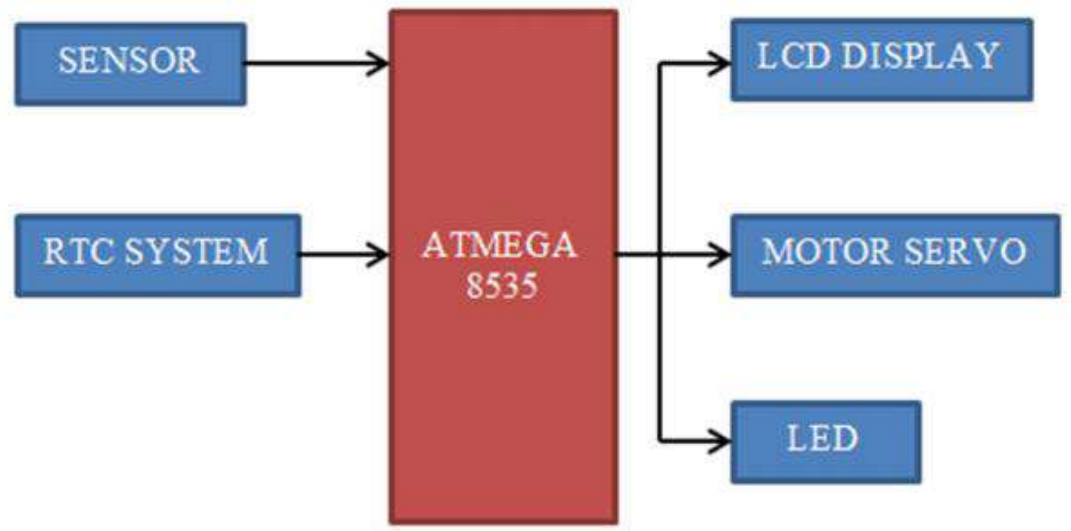

Gambar 1. Blok diagram rancangan dan sistem kerja alat

\subsection{Perancangan Perangkat Keras (Hardware)}

\subsubsection{Rangkaian Mikrokontroler ATmega8535}

Rangkaian mikrokontroler ATMega8535 ini merupakan sistem kontrol yang mengolah datamasukkan dari sensor dan keluaran berupa tampilan nilai pada LCD. Selain itu perintah daripengaturan RTC yang kemudian difungsikan untuk membuka motor servo plat pakan ikan.

\subsubsection{Rangkaian RTC (Real Time Clock) Sistem}

Rangkaian RTC sistem memiliki fungsi menyimpan tanggal, waktu/jam, menit, dan detiksebagai input data pewaktu mikrokontroler yang dihubungkan melalui Port B mikrokontroler.Rangkaian catu daya dapat dilihat pada Gambar 2.

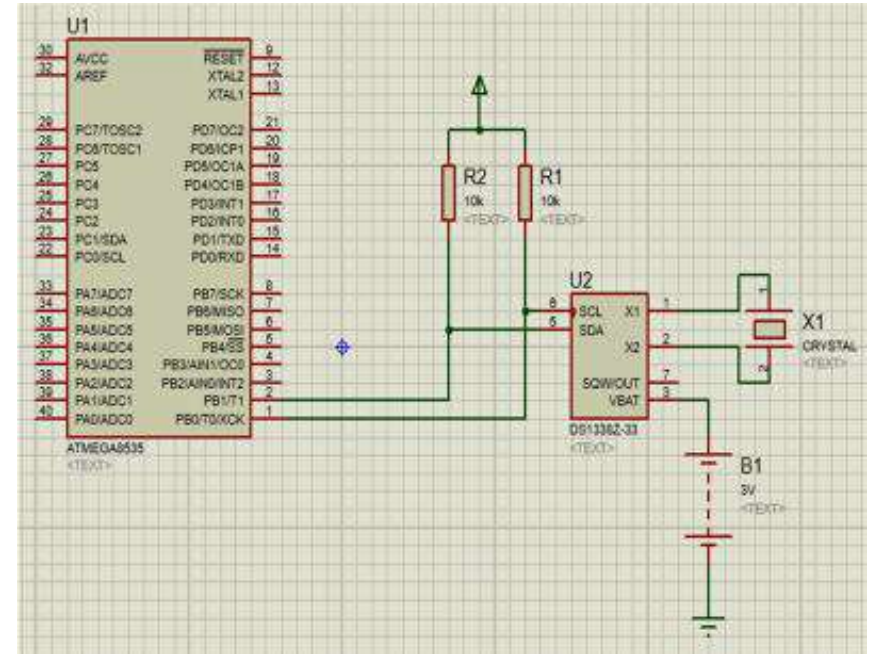

Gambar 2. Rangkaian RTC sistem

\subsubsection{Rangkaian Sensor GE Turbidity}

Fungsi driver relay untuk mengatur keadaan motor dari kondisi on atau off tanpa adanya campur Rangkaian sensor GE turbidity dalam penelitian ini berupa LDR, LED, dan beberapa komponen pendukung lainnya yang digunakan untuk mengindikasi kekeruhan air pada kolam. Rangkaian sensor GE turbidity dapat dilihat pada Gambar 3. 


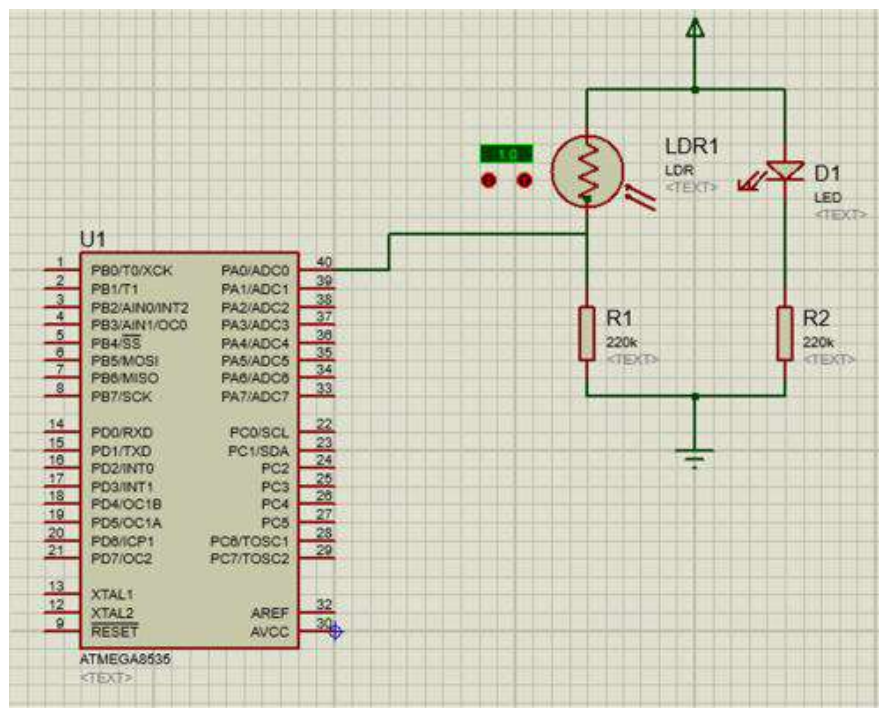

Gambar 3. Rangkaian sensor GE turbidity

\subsubsection{Rangkaian Regulator (IC LM7805T)}

IC LM7805T pada rangkaian ini berfungsi sebagai pembatas tegangan yang masuk atau bisaberfungsi untuk menyaring tegangan yang besarnya lebih dari $5 \mathrm{~V}$ dan diubah ke tegangan $5 \mathrm{~V}$ sesuai dengan yang diinginkan oleh rangkaiannya. Rangkaian regulator LM7805 dapat dilihat pada Gambar 4.

\subsubsection{Rangkaian Penguat Operasional LM358}

Penguat operasional atau yang disebut op-amp adalah suatu jenis penguat elektronika dengan arus searah yang memiliki bati (gain) sangat besar dengan dua masukan dan satu keluaran. Fungsi dari rangkaian op-amp ini digunakan sebagai penguat tegangan dari sensor kerangkaian ADC. Berikut rangkaian skematik penguat operasional dengan menggunakan LM358 dapat dilihat pada Gambar 5.

\subsubsection{Perancangan Perangkat Lunak (Software)}

Sebelum memulai membuat suatu program yang nyata, langkah awal yang dilakukan adalahmembuat alur program (flowchart) terlebih dahulu. Flowchat memiliki peranan penting dalampembuatan sebuah program agar program tersebut bekerja sesuai dengan yang diharapkan. Perancangan diagram alir (flowchat) ini dibagi menjadi dua yaitu perancangan diagram alir pakanikan dan perancangan diagram alir pemantau kekeruhan air. Berikut diagram alir (flowchart) dapat dilihat pada Gambar 6.

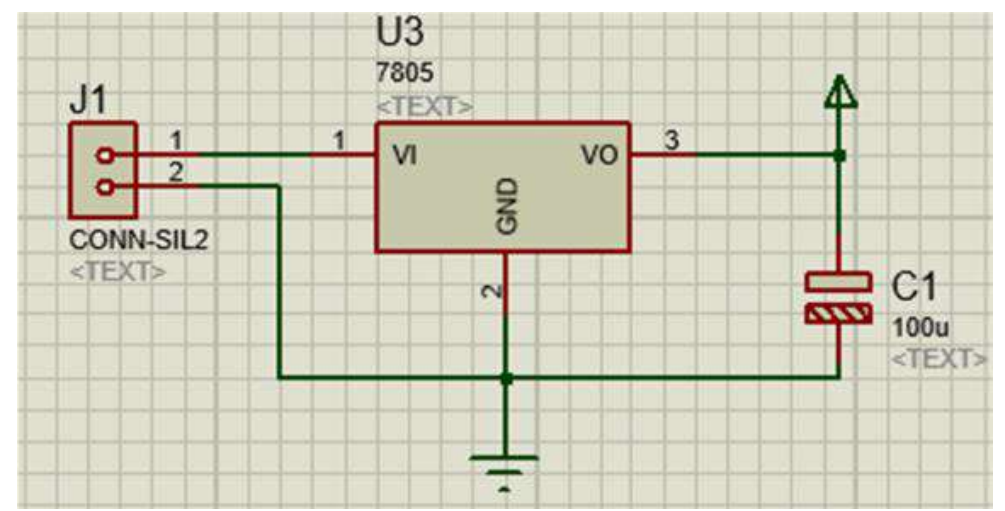

Gambar 4. Rangkaian regulator LM7805 


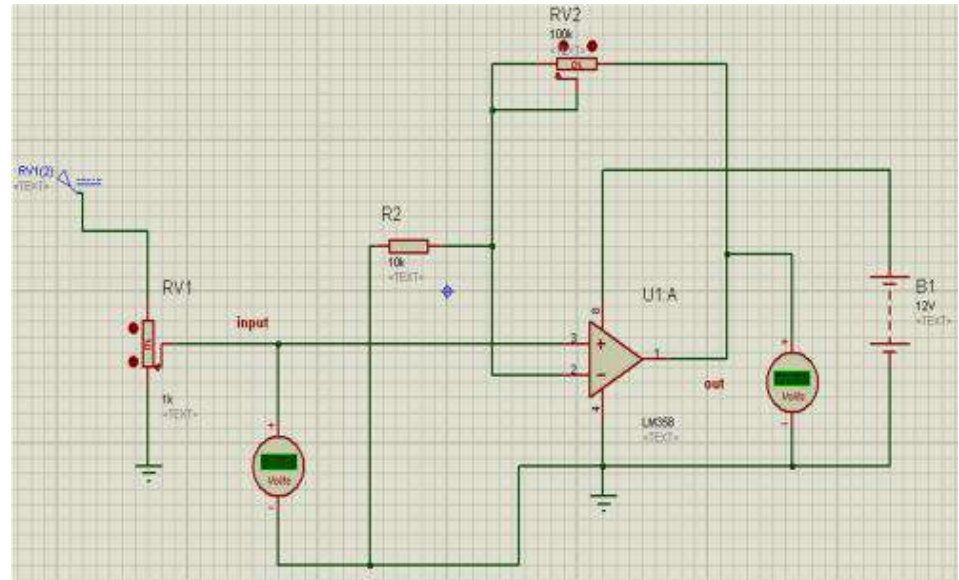

Gambar 5. Rangkaian skematik penguat operasional LM358

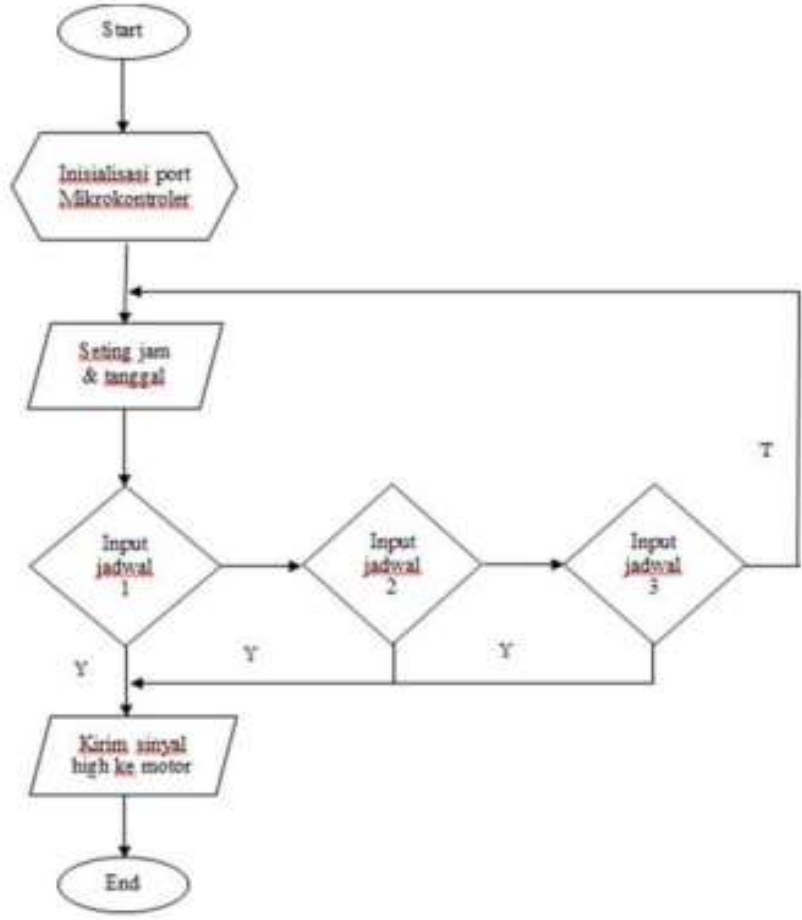

a

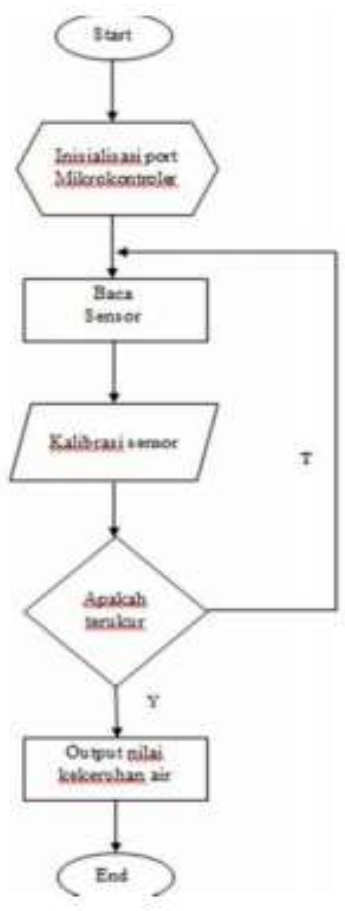

b

Gambar 6. Diagram alir pakan ikan (a), monitoring kekeruhan air (b)

\section{Hasil dan Pembahasan}

\subsection{Pengujian Sensor GE Turbidity}

Pengujian sensor GE turbidity ini dilakukan dengan beberapa cara, yang pertama yaitu dengan memberikan catu daya 5 volt pada sensor, ketika sensor dirasa sudah aktif maka langkah selanjutnya adalah mengkalibrasi sensor dengan cara mencelupkannya kedalam air putih bersih, kemudian putar potensio pada penguat op-amp atur hingga angka pada LCD menunjukkan angka 0. Selanjutnya celupkan sensor turbidity ini ke beberapa sempel air dan hasil pembacaan nilai kekeruhannya akan di tampilkan pada LCD pada Gambar 7(a). Setelah pengujian dilakukan langkah berikutnya adalah pengujian pada sempel air kolam ikan, untuk mengetahui seberapa tinggi tingkat kekeruhannya pada Gambar 7(b). 


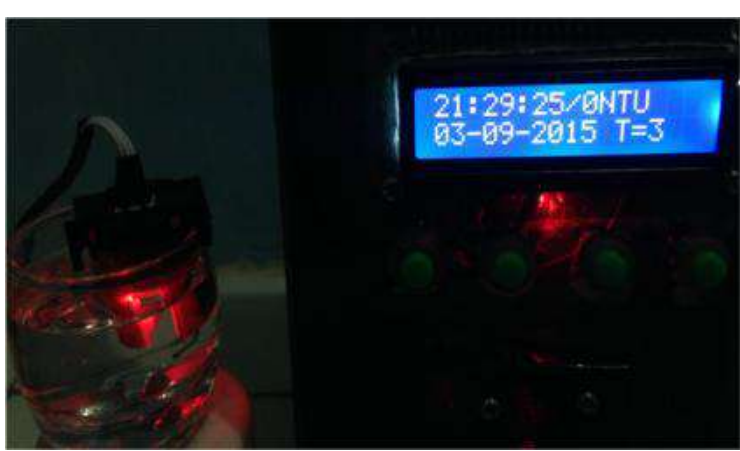

A

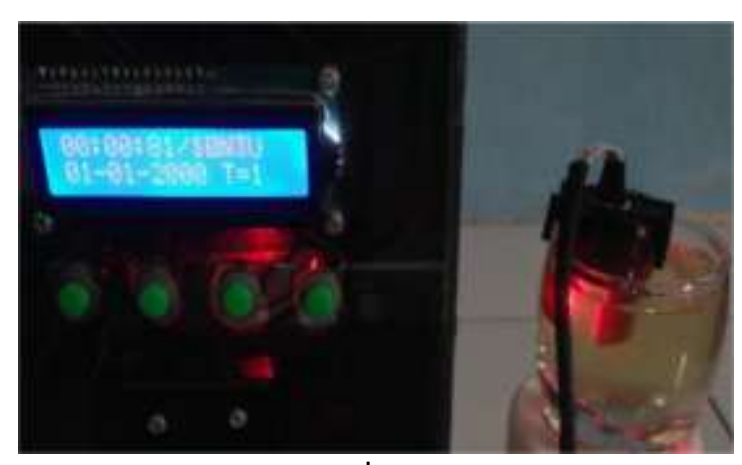

b

Gambar 7. Pengkalibrasian sensor turbidity dengan air putih (a), pengujian sensor turbidity dengan air kolam ikan (b)

\subsection{Pengujian Kekeruhan Air Kolam}

Kualitas air merupakan salah satu faktor yang mendukung keberhasilan budidaya ikan. Penurunan kualitas air akan menyebabkan timbulnya penyakit, gangguan reproduksi pada ikan, pertumbuhan ikan terhambat, pengurangan rasio konversi pakan bahkan dapat menyebabkan kematian. Adapun parameter kualitas air yang bisa diamati yaitu kandungan oksigen terlarut, tingkat keasaman, suhu, dan amoniak. Adapun kualitas air yang dianggap baik untuk kehidupan ikan nila dapat dilihat pada Tabel 2 berikut.

Tabel 2. Kualitas air untuk ikan nila

\begin{tabular}{cll}
\hline No & \multicolumn{1}{c}{ Parameter } & \multicolumn{1}{c}{ Kandungan air yang dianjurkan } \\
\hline 1 & Suhu & $25-30^{\circ} \mathrm{C}$ \\
\hline 2 & pH & $6.5-8.5$ \\
\hline 3 & $\begin{array}{l}\text { Oksigen terlarut } \\
(\mathrm{O} 2)\end{array}$ & $>3 \mathrm{mg} / \mathrm{l}$ \\
\hline 4 & Amonia total & Maksimum 1 $(\mathrm{mg} / \mathrm{l}$ total ammonia) \\
\hline 5 & Kekeruhan & Maksimum $50 \mathrm{NTU}$ \\
\hline 6 & $\begin{array}{l}\text { Karbondioksida } \\
(\mathrm{CO} 2)\end{array}$ & Maksimum 11(mg/l) \\
\hline 7 & Nitrit & Minimum 0.1 $(\mathrm{mg} / \mathrm{l})$ \\
\hline 8 & Alkalinitas & Minimum 20 $(\mathrm{mg} / \mathrm{l} \mathrm{CaCO} 3)$ \\
\hline 9 & Kesadahan total & Minimum 20 $(\mathrm{mg} / \mathrm{l} \mathrm{CaCO} 3)$ \\
\hline
\end{tabular}

Proses pengujian kekeruhan air ini dilakukan dengan mengambil beberapa sempel air yang didapat di desa Wungkirsari, Sleman Yogyakarta dengan jenis ikan yang diperilahara adalah jenis ikan Nila. Berikut tabel sempel air kolam ikan yang diperoleh besrta tingkat kekeruhan airnya dapat dilihat pada Tabel 3.

Tabel 3. Sampel air kolam ikan dan tingkat kekeruhannya

\begin{tabular}{llc}
\hline No & Kolam yang diukur & Tingkat kekeruhan (NTU) \\
\hline 1 & Kolam Ikan 1 & 10 NTU \\
\hline 2 & Kolam Ikan 2 & 9 NTU \\
\hline 3 & Kolam Ikan 3 & 4 NTU \\
\hline 4 & Kolam Ikan 4 & 2 NTU \\
\hline
\end{tabular}

Berdasarkan Tabel 3 diatas, dibuatlah sebuah grafik tingkat kekeruhan air kolam mulai dari tingkat air yang keruh hingga tingkat air yang cukup jernih yang dapat dilihat pada Gambar 8. 


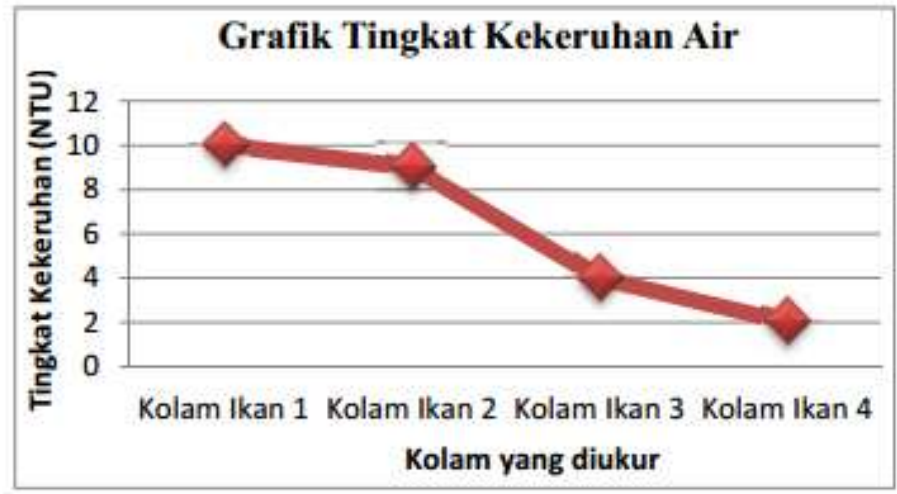

Gambar 8. Tingkat kekeruhan air kolam

Berdasarkan Gambar 8 diatas dapat ditarik kesimpulan bahwa, kolam ikan 1 memiliki tingkat nilai kekeruhan paling tinggi yaitu dengan 10 NTU, sedangkan kolam ikan 2 dengan 9 NTU, kolam ikan 3 dengan nilai kekeruhan 4 NTU, dan kolam dengan tingkat kekeruhan tinggi pada kolam ikan 4 dengan nilai kekeruhan 2 NTU.

\subsection{Pengujian Motor Servo}

Proses pengujian motor servo ini dilakukan dengan tujuan untuk mengetahui apakah motor servo dapat bekerja secara optimal ataukah tidak pada saat penggunaan dan agar didapat data dari suatu sisitem tersebut. Fungsi motor servo nantinya akan menggerakkan plat pada wadah pakan ikan sehingga pakan yang berada di dalamnya dapat ditumpahkan sesuai waktu penjadwalan yang telah di setting.

Sebelum memulai pengujian mula-mula pengguna melakukan penyetingan waktu penjadwalan, ketika penyetingan waktu penjadwalan telah selesai maka pada saat waktu yang telah disetingan dengan waktu real sebenarnya telah sama, motor servo akan membuka plat wadah pakan, sehingga pakan yang berada di dalamnya dapat di tumpahkan. Untuk lebih jelasnya perhatikan Gambar 9 berikut.

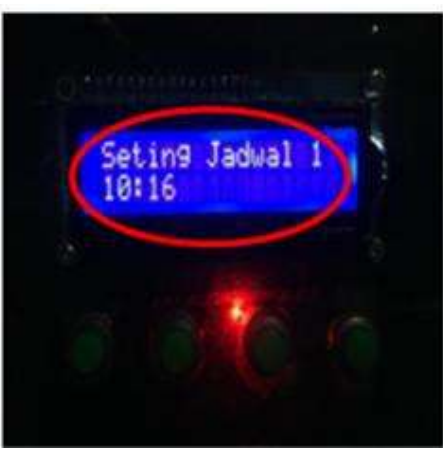

A

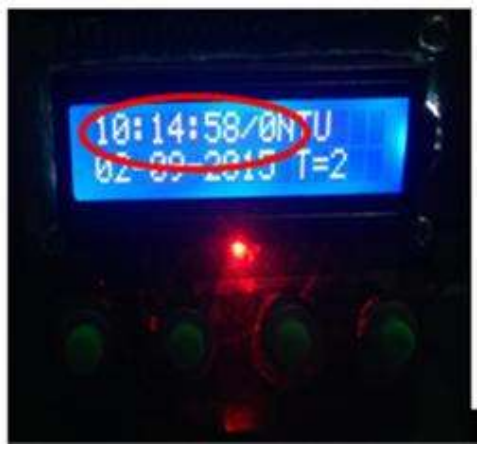

b

Gambar 9. Jadwal seting pakan (a) dan waktu pada LCD (b)

Setelah seting jadwal pakan selesai selanjutnya tunggu beberapa saat sampai waktu yang tertera pada LCD dengan waktu yang telah kita seting tadi sama, setelah kedua waktu telah sama maka secara otomatis motor servo akan bekerja yaitu membuka plat pakan ikan sehingga pakan yang berada di dalamnya dapat ditumpahkan. Untuk lebih jelasnya perhatikan Gambar 10. 


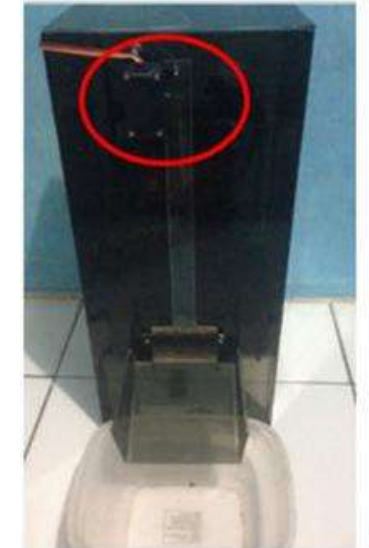

a

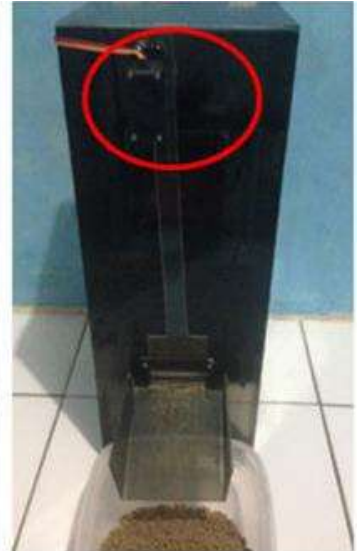

b

Gambar 10. Posisi awal motor servo (a) dan posisi motor saat membuka plat pakan (b)

Gambar 10 menunjukkan posisi pergerakkan motor servo, gambar 4.4 (a) merupakan gambar posisi mula motor servo sebelum bekerja, posisi awal motor servo tersebut berada pada titik -90 derajat $(90$ derajat ke kiri) $=0$ derajat. Sedangkan untuk gambar 4.4 (b) merupakan gambarposisi motor servo saat membuka plat pakan, pada saat ini posisi motor servo berada pada titik 0 derajat (tengah-tengah) $=90$ derajat.

\subsection{Pengujian Jumlah Pakan Ikan}

Pengujian kali ini menggunakan pelet ikan yang mempunyai ukuran butiran relatif kecil dan umumnya berwarna kecoklatan, pelet ini dipilih karena selain memiliki ukuran yang relatif kecil pelet ini juga memiliki tekstur yang halus sehingga mempermudah saat pengujian pada alat.

Konversi yang efisien dalam memberi makan ikan sangat penting bagi pembudidaya ikan sebab pakan merupakan komponen yang cukup besar dari total biaya produksi. Bagi pembudidaya ikan, pengetahuan tentang gizi bahan baku dan pakan merupakan sesuatu yang sangat kritis sebab pakan menghabiskan biaya $40-50 \%$ dari biaya produksi. Jumlah pakan harian yang diberikan pada setiap kolam (DFA) nilai DFA dapat dihitung dengan menggunakan rumus sebagai berikut

Keterangan :

$$
D F A=W \times N \times S R \times R
$$

$W$ = bobot rata-rata ikan / ekor selama masa pemeliharaan yang ditentukan.

$N=$ jumlah ikan pada awal penebaran (ekor).

$S R$ = perkiraan kelangsungan hidup selama masa pemeliharaan yang ditentukan.

$R \quad$ = banyaknya pakan yang diberikan (feeding rate).

Misal pemberian pakan sebesar $6 \%$ per hari dari jumlah bobot ikan yang dipelihara pada satu kolam. Jumalah ikan dalam kolam katakanlah 300 ekor, dengan berat per ekor 50 gram dengan perkiraan kelangsungan hidup adalah $90 \%$. Maka jumlah pakan yang diberikan untuk satu hari adalah:

$$
50 \text { gram } \times 300 \text { ekor } \times 90 \% \times 6 \%=810 \text { gram } / 0.81 \mathrm{~kg}
$$

Jadi jumlah/ pakan ikan yang diberikan adalah sebanyak 810 gram atau $0.81 \mathrm{~kg} / \mathrm{hari}$. Berdasarkan perhitungan diatas maka hitungan untuk 1 kali makan dalam 3 kali sehari adalah

$$
\frac{0.81 \mathrm{~kg} / \mathrm{hari}}{3}=0.27 \mathrm{~kg}=270 \mathrm{gram}
$$


Jurnal IImu Teknik Elektro Komputer dan Informatika (JITEKI)

Vol. 2, No. 1, Juni 2016

Sehingga pemberian makan ikan setiap 1 kali pemberian adalah 270 gram, pada alat pakan ikan otomatis ini agar didapat perhitungan berat sebesar 270 gram tersebut perlu di setting waktu buka pakan ikan. Waktu yang dibutuhkan agar pakan yang di tumpahkan menghasilkan berat sekitar \pm 270 gram adalah 23 detik. Berikut hasil pengujian jumlah pakan per 2 detik dapat dilihat pada Tabel 4 .

Tabel 4. Jumlah pakan ikan keluar

\begin{tabular}{ccc}
\hline Pengujian & Durasi waktu plat & Banyaknya pakan yang \\
\hline ke & terbuka (detik) & dijatuhkan (gram) \\
\hline 1 & 2 & 27.14 \\
\hline 2 & 4 & 50.3 \\
\hline 3 & 6 & 73.71 \\
\hline 4 & 8 & 96.3 \\
\hline 5 & 10 & 120.3 \\
\hline 6 & 12 & 143.6 \\
\hline 7 & 14 & 166.52 \\
\hline 8 & 16 & 190.03 \\
\hline 9 & 18 & 214.21 \\
\hline 10 & 20 & 238.04 \\
\hline 11 & 22 & 261.23 \\
\hline 12 & 23 & 274.2 \\
\hline 13 & 23 & 273.7 \\
\hline
\end{tabular}

Perhitungan diatas diasumsikan jumlah ikan adalah 300 ekor dengan berat rata-rata ikan 50 gram, apabila jumlah dan berat rata-rata ikan lebih besar maka jumlah pakan yang dibutuhkan dalam 1 hari akan lebih banyak. Karena pemberian banyak sedikitnya makan ikan tergantung juga dari jumlah dan berat rata-rata pada ikan tersebut. Untuk lebih jelasnya berikut penulis berikan tabel asumsi perhitungan pakan ikan dapat dilihat pada Tabel 5 dibawah.

Tabel 5. Asumsi perhitungan pakan ikan

\begin{tabular}{|c|c|c|c|c|c|c|}
\hline Bulan & Asumsi & Jumlah & $\%$-ase & $\%$-ase & Jumlah & Jumlah \\
\hline ke & Berat & Bibit & pakan & kelangsungan & pakan & pakan per \\
\hline & Ikan (gr) & & & hidup & per hari & Bulan (kg) \\
\hline & & & & \multicolumn{3}{|c|}{$(\mathrm{kg})$} \\
\hline 1 & 10 & 300 & 8 & 90 & 0.216 & 6.48 \\
\hline 2 & 50 & 300 & 6 & 90 & 0.81 & 24.3 \\
\hline 3 & 100 & 300 & 5 & 90 & 1.35 & 40.5 \\
\hline 4 & 150 & 300 & 4 & 90 & 1.62 & 48.6 \\
\hline 5 & 200 & 300 & 4 & 90 & 2.16 & 64.8 \\
\hline \multirow[t]{2}{*}{6} & 250 & 300 & 3 & 90 & 2.025 & 60.75 \\
\hline & & & & & Jumlah & 245.43 \\
\hline
\end{tabular}

\section{Kesimpulan}

Berdasarkan hasil dari pengujian alat dapat ditarik beberapa kesimpulan sebagai berikut :

1. Alat pemberian pakan ikan ini mudah dan baik digunakan karena selain otomatis dan terjadwal alat ini mampu memonitoring kekeruhan air sehingga pengguna dapat melakukan tindakan selanjutnya. 
Jurnal IImu Teknik Elektro Komputer dan Informatika (JITEKI)

Vol. 2, No. 1, Juni 2016

2. Melihat dari hasil pengujian pakan motor servo Futaba $\$ 3003$ yang digunakan mampu untuk membuka plat pakan sehingga pakan yang berada didalam wadah dapat ditumpahkan.

3. Berdasarkan data yang diperoleh alat dapat bekerja dengan baik karena pada saat pengujiannya dengan rentang waktu pemberian tiap 2 detik hasil data yang diperoleh adalah linear.

4. Berdasarkan percobaan yang telah dilakukan sensor GE turbidity TST-10 yang digunakan mampu mengukur tingkat kekeruhan air dari 4 kolam.

\section{Referensi}

[1] Hakim, Lukman. 2009. Sistem Pengaman Kendaraan Bermotor Menggunakan SMS Berbasis Mikrokontroler AVR ATMega8535. Yogyakarta : Universitas Negeri Yogyakarta.

[2] Wahyudi, Teguh. 2011. Sistem Keamanan Rumah dengan Menggunakan Motion Dan SMS Gateway. Jawa Timur: Universitas Pembangunan Nasional "VETERAN".

[3] Sumarsela, Febryana. 2010. "Pembuatan Pototype System Pengaman Kendaraan Bermotor Berbasis Mikrokontroller dan SMS Gateway". Jawa Timur: Prodi Teknik Informatika Universitas Pembangunan Nasional "VETERAN".

[4] Edi, Rizki. 2012. Media Pembelajaran Mikrokontroler AVR. Yogyakarta : Universitas Negeri Yogyakarta

[5] www.intellitrac.co.id,"statistik-kriminalitas-indonesia-2014". (diambil pada tanggal 4 Januari 2015 )

[6] www.selular88.com," Perbedaan Modem Wavecom 1206B \& 1306B" ( diambil pada tanggal 5 Januari 2015 ).

[7] www.wavecom.com," Product Modem Wavecom GSM". ( diambil pada tanggal 5 Januari 2015 )

[8] www.smartdraw.com, ( diambil pada tanggal 6 Januari 2015)

[9] www.Datasheet.com. (diambil pada tanggal 6 Januari 2015 )

[10] www.electusdistribution.com, "Relay Driving Basics ". ( diambil pada tanggal 10 Januari 2015 )

[11] Bejo, Agus. 2008. Rahasia Kemudahan Bahasa C dalam Mikrokontroler ATMega8535. Yogyakarta: Graha IImu.

[12] Cooper, W. D. 1985. Intrumentasi Elektronika Dan Teknik Pengukuran. Jakarta: Erlangga.

[13] Jacob, J., M. 1989. Industrial Control Electronics applications And Design. United States of America: Prentice-Hall,Inc.

[14] Atmel Corporation. 2015. Datasheet ATmega8535. Diperoleh dari: www.atmel.com (29 Agustus 2015).

[15] Bishop, Owen. 2002. Dasar-Dasar Elektronika (Seri Profesi Elektronika) : Penerbit Erlangga.

[16] Firdausy, K. 2008. Modul Praktek Bahasa Pemrograman. Yogyakarta: Teknik Elektro, Universitas Ahmad Dahlan

[17] Innovative Electronics. 2003. Bring Tecnology To Your Hand. Diperoleh dari : http://www.innovativeelectronics.com/ (Diakses 29 Agustus 2015).

[18] Innovative Electronics (2003). Rangkain Expansion Socket AVR. Diperoleh dari : http://www.innovativeelectronics.com/ (Diakses 30 Agustus 2015).

[19] Winoto, A. 2008. Mikrokontroler AVR Atmega8/ 16/32/8535 dan Pemrogramannya dengan Bahasa $C$ pada WinAVR. Bandung: Informatika.

[20] www.mpm-motor.co.id, (diambil pada tanggal 3 januari 2016 ). 